Information Structure: Notional Distinctions, Ways of Expression

Running Title: Information Structure

Prof. Dr. Caroline Féry

Institut für Linguistik

Universität Potsdam

Karl-Liebknecht-Str. 24-25

D-14476 Golm

caroline.fery@googlemail.com

Prof. Dr. Manfred Krifka

Institut für deutsche Sprache und Linguistik

Humboldt-Universität zu Berlin

Unter den Linden 6

10099 Berlin

krifka@rz.hu-berlin.de 


\title{
Information Structure: Notional Distinctions, Ways of Expression
}

\author{
Caroline Féry and Manfred Krifka
}

\begin{abstract}
Information Structure, the packaging of information to satisfy the immediate communicative needs, exerts a powerful force on all structural levels of language. We show how this concept can be defined, we argue for focus, givenness, topic, frame setting and delimitation as important subconcepts, and we illustrate the wide variety in which these information structural functions are expressed in languages.
\end{abstract}

\section{What is Information Structure?}

The phenomena we subsume under the notion of information structure (IS, for short) have enjoyed the attention of linguists for a long time. They have been identified since the medieval Arab grammatical tradition by different linguistic schools in a number of ways. To mention the perhaps most influential one, the Prague School initiated by Mathesius has argued that the identification of given material (the theme) and the highlighting of new material (the rheme) exerts a powerful force on language structure. Today, the effects of IS are recognized in every theoretic framework that strives for a comprehensive view of linguistic structure, and they are investigated in a wide variety of distinct languages - witness the contributions to the Parallel Session on Information Structure at CIL 18.

But what is IS? Following Chafe (1976), we understand it to refer to the packaging of information that meets the immediate communicative needs of the interlocutors, i.e. the techniques that optimize the form of the message with the goal that it be well understood by the addressee in the current attentional state. One such feature, for example, is the highlighting of constituents, called focus. In (1), a question creates a particular attentional state, which is recognized by the focus in the answer, expressed by pitch accent on tiger (cf. 1a). Pitch accent on road, as in (1b), would lead to an infelicitous answer, even though the truth conditions of (1a) and (1b) are the same, as it does not fit to the context question.

(1) $\quad$ What did you see on the road?\}

a. We saw a TIGER on the road.

b. \#We saw a tiger on the ROAD. 
Chafe's metaphor of packaging suggests that IS never affects truth conditions. However, one shold be aware of the fact that the markings of IS can have truth-conditional effects, for example with focus-sensitive particles like only. In (2a), the speaker may have seen other animals on the road, but the only place where a tiger was spotted was on the road. In (2b), no other animal was seen there. Depending on the placement of the pitch accent, this English sentence is true in different contexts.

(2) a. We only saw a tiger on the ROAD.

b. We only saw a TIGER on the road.

One and the same linguistic device, sentence accent, can be used for packaging as well as for constructing the truth-conditional content. There are two ways of dealing with this: One is to assume that the two uses of the same feature are essentially unrelated, just as the uses of accent in English to express focus and to distinguish words such as REcord and reCORD. The other is to assume that the feature is to be interpreted in a particular way that makes sense for the purposes of information packaging and of building information content. The second alternative is more attractive, as we should not assume multiple meanings if possible. We will see that focus indeed can be interpreted in this way.

We will first provide definitions of the notions of IS, and then examine some of the linguistic means used for the realization of IS. The grammatical devices for focusing, defocusing or topicalizing will turn out to be parts of a set of reflexes existing independently in the language under consideration. We wish to point the readers to Féry, Fanselow \& Krifka (ed.) (2006) for a more comprehensive exposition of some of the points discussed here.

\section{The notions of information structure}

If we want to talk about communication as transfer of information and its optimization relative to the momentary needs of interlocutors, it is useful to adopt a model of information exchange rooted in the notion of Common Ground. The original notion of CG (cf. Stalnaker 1974) saw it as a way to model the information that is mutually known to be shared, which is continuously modified in the course of communication. This allowed for modeling the distinction between presuppositions, as requirements for the input $\mathrm{CG}$, and assertions or the proffered content, as the proposed change in the output CG. This distinction is relevant for information packaging, as the CG changes continuously, and information has to be packaged corresponding to the $\mathrm{CG}$ at the point at which it is uttered.

CG does not only consist of a set of propositions that is presumed to be mutually accepted, but also of a set of entities that have been introduced into 
the CG before, the discourse referents. They can be taken up by pronouns or by definite NPs, which express requirements to the input CG. The choice of anaphoric expression depends on the recency of the antecedent, again a notion that falls squarely within Chafe's notion of packaging.

The properties of CG mentioned so far have to do with the truth-conditional information in the $C G$, so we can subsume them under the heading of $C G$ content. But any notion of CG that can be applied to the analysis of real communication must also contain information about the manifest communicative interests and goals of the participants. For example, questions typically do not add factual information to the common ground, but indicate informational needs on the side of one participant that should be satisfied by a conversational move of the other. We call this dimension of the common ground CG management, as it is concerned with the way the CG content is supposed to develop. Just as CG content, the tasks of CG management is shared by the interlocutors, with the understanding that the responsibility for it may be asymmetrically distributed among participants.

Turning now to definitions of the IS categories that we consider crucial, we propose first a three-way distinction between focus, givenness and topic.

A general definition of focus, making use of a central insight of Alternative Semantics (Rooth 1992), appears in (3).

(3) Definition of focus:

Focus indicates the presence of alternatives that are relevant for the interpretation of linguistic expressions.

One prominent use of focus is the identification of context questions in answers, as in (1). The idea is that the meaning of a question identifies a set of alternative propositions, the answer picks out one of these, and the focus within the answer signals the alternative propositions inherent in the question.

The alternative denotations indicated by focus have to be comparable to the denotation of the expression in focus, i.e. they have to be of the same type, and often also of the same ontological sort (e.g., persons or times). They also can be more narrowly restricted by the context of utterance. The complement of focus is 'background.'

The second notion to be defined is givenness:

(4) Definition of givenness:

A feature $\mathrm{X}$ of an expression $\alpha$ is a Givenness feature iff $\mathrm{X}$ indicates whether the denotation of $\alpha$ is present in the CG or not, and/or indicates the degree to which it is present in the immediate CG.

Schwarzschild (1999) develops a refined theory of interaction between givenness and focus, which checks givenness recursively and states that constituents not in focus must be given, and that focus has to be applied 
only when necessary, i.e. to prevent that a constituent is given. But while focus is restricted in Schwarzschild's theory, it cannot be eliminated totally. In fact focus/background and given/newness cannot be reduced to just one opposition, as these pairs of notions are only partially overlapping. For example, given expressions, like pronouns, can be focused.

The notion of 'topic' comes with a complementary part called 'comment.' Reinhart (1982) integrates it into a theory of communication that makes use of the notion of CG. According to her, new information is not just added to the CG content in form of unstructured propositions, but is rather associated with entities, just like information in a file card system is associated with file cards that bear a particular heading. A definition based on this insight appears in (6).

(5) Definition of topic:

The topic constituent identifies the entity or set of entities under which the information expressed in the comment constituent should be stored in the CG content.

For example, while $(6 a, b)$ express the same proposition, they structure it differently insofar as (a) should be stored as information about Aristotle Onassis, whereas (b) should be stored as information about Jacqueline Kennedy.

(6) a. [Aristotle Onassis $]_{\mathrm{T}}[\text { married Jacqueline Kennedy }]_{\mathrm{C}}$

b. [Jacqueline Kennedy $]_{\mathrm{T}}$ [married Aristotle Onassis $]_{\mathrm{C}}$

Theories of IS often introduce additional notions beyond focus, givenness and topic. One such notion is contrast, which is distinguished from pure information focus that shows up, e.g., in the answer to constituent questions. With contrast, the alternatives have to be given explicitly, and usually it is also assumed that only one of the contrasted alternatives is acceptable. For example, answers to alternative questions would qualify as having contrastive focus:

(7) A: Do you want TEA or COFFEE?

B: I want TEA.

There is a plausible argument that we do not need contrastive focus as a separate basic notion, as we already have introduced givenness; hence contrastive focus can be defined as that subtype of focus in which the alternatives are given. The uniqueness assumption may follow if we assume that apparent non-uniqueness arises because alternatives can be combined (e.g., we saw a tiger and a baboon on the road), but that the explicit enumeration of alternatives that does not include a combination (e.g., or both in (7.A)) suggests that such combinations should be disregarded.

Another important notion is contrastive topic, as in the following example: 
(8) A: What are your sisters playing?

B: My YOUNGER sister plays the VIOLIN, and my OLDER sister, the FLUTE.

The phrase my YOUNGER sister is a contrastive topic. Rising accent indicates that at the current position of discourse, other topics could have been chosen (e.g, my OLDER sister). Again, we do not need contrastive topic as a basic notion. If focus, in general, indicates the presence of alternatives, then focus within a topic would indicate the presence of alternative topics at the current point in discourse. In (8), the choice of my YOUNGER sister as topic indicates that there are other possible topics that can be described by my X sister; and indeed, the second clause, my OLDER sister identifies such an alternative topic. Contrastive topics are to be expected whenever a question is too complex to be answered on the basis of one single topic; they indicate a particular answering strategy by introducing subtopics (cf. Büring 2003).

There is a phenomenon that is somewhat related to topichood, which has been called frame setting (cf. Jacobs 2001).

(9) A: How is John?

B: $\{$ Healthwise / As for his health $\}$, he is FINE.

This is a statement about John, but it is restricted to those aspects that concern John's health (in contrast, e.g., to his financial sitation). We call phrases like healthwise "frame setters". Clearly, focus plays a role with frame setters, just as with contrastive topics, as they express a certain restriction of the ensuing predication to some perspective that is not clearly identified by the context already - if the health perspective were already established, there would be no need to express it explicitly. Frame setters restrict context-sensitive expressions, like be fine, to the specified dimension, or delimit the predications that can be made. For example, As for his health, he had a serious flu recently is fine, but As for his financial situation, he has a serious flu recently is not.

There is an obvious similarity between contrastive topics and frame setters that is reflected in the way how these information-structural functions are marked (e.g., by a B-accent in English, or by the postposition nun in Korean). Both express that the predication is restricted in some way - e.g., (8b) restricts the predication plays the violin to the younger sister (where the expected value is the sisters in general), and (9) restricts the predication to aspects concerning John's health. It is useful to introduce a new term for this function: delimitation. It is a genuin phenomenon of IS, as it responds to the current informational need of the addressee: It is indicated that the issue at hand is broader, and that the ensuing speech act concerns only a part of this more general issue. Hence, delimitation can be defined as follows:

(10) Definition of Delimitation

A delimiter $\alpha$ in within an expression $[\ldots \alpha \ldots .$.$] always comes$ with a focus within $\alpha$ indicating alternatives $\alpha^{\prime}, \alpha^{\prime \prime}$ etc. 
It indicates that the current informational need is not totally satisfied by $[\ldots \alpha \ldots]$ but would be satisfied by additional expressions $\left[---\alpha^{\prime}---\right],\left[\alpha^{\prime \prime}---\right]$ etc.

We do not claim that the notions of focus, givenness, topic, frame setting and delimitation exhaust what there is to say about IS. For example, in an argumentative discourse, the current informational need might dictate the selection and ordering of arguments to gain support for a particular conclusion. But such effects go beyond the limit of the sentence, and relate it to discourse structure. Here we will stay within the confines of the sentence (in a particular context), and we will try to illustrate some of the ways in which the IS notions specified above are expressed in languages.

\section{The expression of information structure}

How do languages mark the various IS distinctions? While there is considerable variety in the strategies that we find in different languages, they always have a relationship to prosody: focus tends to be prosodically prominent, and givenness tends to be prosodically non-prominent, while topic tends to form a separate prosodic phrase, and is thus also prominent (the same holds for frame setters and delimiters in general). But this prosodic connection is achieved by different grammatical correlates in different languages, depending on the languages' general properties. And languages differ in the obligatoriness of expressing IS distinctions; for example, it has been shown that in Northern Sotho (Bantu) and Hausa do not express the focus of answers as rigidly as English (cf. Zerbian 2006, Hartmann \& Zimmermann 2007).

In English, focus and topic correlate with pitch accents, and givenness is often expressed by deaccenting, see (1) and (2). But in a number of Asian and African languages, pitch accents only play a minor role, if at all, and morphological and syntactic means are prevalent. In tone languages, phrasing can replace the pitch accents of intonation languages, and particles can play the role of boundary tones. An extreme case of prosodic marking of IS is ellipsis, where only the focused part of a sentence is pronounced, and the given part is just deleted.

Following Jackendoff (1972), we assume that IS roles are identified at the surface syntactic structure by features, in the way shown in (11) to (13).

(11) a. We only saw a tiger [on the ROAD] $]_{\mathrm{F}}$.

b. We only saw $[\text { a TIGER }]_{\mathrm{F}}$ on the road.

(12) \{What did you see on the road?\}

$[\text { We saw }]_{\mathrm{G}}[\text { a TIGER }]_{\mathrm{F}}[\text { on the road }]_{\mathrm{G}}$. 
(13) $[\text { As for tigers, }]_{\mathrm{T}}[\text { we saw one on the road }]_{\mathrm{F}}$.

We examine syntactic, phonological and morphological reflexes of IS in the next subsection, and show in each case how they relate to prosody.

\subsection{Sentence Position}

First, IS roles are often associated with sentence positions. Halliday (19678 ) holds that the initial position is a necessary condition for a 'theme' (a topic in our terminology). This preferred place for a topic is easily explained: since it is the address at which the infomration of the sentence is supposed to be stored, it makes sense to introduce it right at the beginning. However, topic are not necessarily located sentence-initially. In the following Korean sentence, the topic dezaato-wa 'dessert' is placed after a quantifier phrase and is thus not initial. ${ }^{1}$ A subscript $\mathrm{P}$ shows a prosodic phrase (p-phrase), and a subscript I a larger intonation phrase (i-phrase).

(14) $\left((\text { Nwukwuna-ka })_{\mathrm{P}}\left([\text { dessert-nun }]_{\mathrm{T}}\right)_{\mathrm{P}}(\text { ice cream-ul mek-ess-ta })_{\mathrm{P}}\right)_{\mathrm{I}}$ everyone-NOM dessert-TOP ice cream-ACC eat-PAST-DEC 'As for dessert, everyone ate ice cream.'

Sentence-final topics, sometimes called 'anti-topics' are also possible, as illustrated in (15) for Cantonese and (16) for French.

(15) $\left((\text { Go loupo })_{\mathrm{P}}(\text { nei gin-gwo gaa })_{\mathrm{P}},\left([\text { ni go namjan ge }]_{\mathrm{T}}\right)_{\mathrm{P}}\right)_{\mathrm{I}}$. CLF wife 2.SG see-EXP DSP this CLF man DSP 'The wife you have seen, of this man.'

(16) $\left((\text { Pierre l' a mangée })_{\mathrm{P}}, \quad\left([\text { la pomme }]_{\mathrm{T}}\right)_{\mathrm{P}}\right)_{\mathrm{I}}$.

Peter it-ACC has eaten, the apple

'Peter has eaten the apple.'

The common property of topics is their separation from the remainder of the sentence. They tend to form their own i-phrase (intonation phrase), which allows for a clear intonational separation. In languages like Japanese or Cantonese, particles not only signal the role of the constituent as a topic, but also add place for a boundary tone. This allows the topic in (16) to be inserted in a non-initial position.

Focus has also been associated with special positions in certain languages. Hungarian has been described as a language which obligatorily places an exhaustive focus preverbally (É. Kiss 1998), and Italian as a language with clause-initial (Rizzi 1997) or clause-final (Samek-Lodovici 2006) foci.

1 Thanks to Shin-Sook Kim for providing this sentence. 
An alternative explanation, which accounts for the Hungarian facts without forcing an association between focus and preverbal position, assumes that Hungarian is phonologically a left-headed language, both for prosodic words and prosodic phrases. Focus wants to be prominent and the preferred stress position is at the beginning of the main i-phrase, directly after the iphrase of the topic. The initial position is occupied by the narrow focus, as often as possible, and happens to be the verb in all other cases (see Szendröi 2003). But focus may also be located postverbally: In (17), both the VP and the dative object are focused and the accusative object is given, but the dative object is postverbal. In such cases, focus is indicated by pitch accent only.

(17) $\left((\text { Tegnap este })_{\mathrm{P}}\right)_{\mathrm{I}}\left((\text { BEMUTATTAM Pétert })_{\mathrm{P}}(\text { MARINAK })_{\mathrm{P}}\right)_{\mathrm{I}}$. yesterday evening PRT-introduced-I Peter.ACC Mary.DAT 'Yesterday evening, I introduced Peter to Mary.'

In Italian, given elements may be moved out of the matrix clause, and typically, it is this movement which causes finality of focus. In (18), adapted from Samek-Lodovici (2006), Parigi is the focus, and the following constituents are right-dislocated as they are given. Italian is a language with final stress, both at the level of the p-word, where it is trochaic, and at the level of the p-phrase, and syntactic reorganization helps prosody in moving narrow foci to the furthest possible rightward position. Thus, both in Hungarian and in Italian the peripheral position of focus is not a special feature of focus, but reflects the general preference for prominence.

(18) $\left.\left((\mathrm{L} \text { 'ho incontrato [a PARIGI }]_{\mathrm{F}}\right)_{\mathrm{P}},(\text { Luigi })_{\mathrm{P}},(\text { ieri })_{\mathrm{P}}\right)_{\mathrm{I}}$.

(I) him have-met in Paris, Luigi, yesterday 'I met Luigi in Paris yesterday.'

\subsection{Accents}

There have been numerous attempts in the literature to relate specific information roles to the form of pitch accents. Bolinger (1958) introduces a distinction between accent $\mathrm{A}$, a falling accent, and accent $\mathrm{B}$, a fall-rise accent, for English, and Jackendoff (1972) and Liberman \& Pierrehumbert (1984) relates the former to focus and the latter to topic, as in (19). Manny has accent B, and Anna accent A.

(20) \{What about Manny? Who did he come with?\} $\left(\left([\mathrm{MANNY}]_{\mathrm{T}}\right)_{\mathrm{P}}\left(\text { came with }[\mathrm{ANNA}]_{\mathrm{F}}\right)_{\mathrm{P}}\right)_{\mathrm{I}}$.

Büring (2003), for German, and Steedman (2000), for English, establish an obligatory relationship between contours and roles by having pitch accent contours participate in the definition of topics and foci. Attempts to relate forms of accents to specific IS roles are found for other languages as well. 
For instance, Frota (2000) claims that narrow foci in Portuguese are always associated with a certain kind of accent.

An alternative explanation is possible which only indirectly relates IS to the forms of accents.. The preference for associating specific contours with IS roles can be explained by general properties of the language. As far as topics are concerned, the preference for sentence-initiality is paired with a preference for rising tones. The rising tone is just a reflex of the non-finality of this accent. And the falling contour often found on focus may be related to the late position of a focus in a sentence.

Do languages with pitch accents necessarily use them for topics and foci? The question bears on the necessity of accents (and of deaccenting) in general in relation to focus/topic/givenness. Jackendoff formulates a rule which directly relates a focus with an accent. 'If a phrase $\mathrm{P}$ is chosen as the focus of a sentence $\mathrm{S}$, the highest stress in $\mathrm{S}$ will be on the syllable of $\mathrm{P}$ that is assigned highest stress by the regular stress rules' (1972:247). Nearly all models relating focus with phonology rely on a direct correspondence between semantics and phonetics and require an accent signaling the presence of a focused constituent (see for instance Cinque 1993, Rooth 1992, Selkirk 1995, Schwarzschild 1999, and many others).

But in fact, there are examples in which the association between focus and accent seems to be cancelled. One such case is the so-called Second Occurrence Focus (cf. Partee 1999, Beaver et al. 2007, Féry \& Ishihara 2005), which combines elements of association with focus and givenness. Only vegetables in (21b) is associated with the focus operator only, and is thus a focus, but it is also given, because it is repeated from (21a).

(21) a. $\left\{\right.$ Everyone already knew that Mary only eats $\left.[\text { vegetables }]_{\mathrm{F}}\right\}$.

b. If even $[\mathrm{Paul}]_{\mathrm{F}}$ knew that Mary only eats [vegetables $]_{\mathrm{SOF}}$, then he should have suggested a different restaurant.

There are only weak correlates of accent, and no pitch excursions in the postnuclear position, although Féry \& Ishihara (2005) show that a pitch accent is indeed present in the prenuclear position.

Other cases of absence of accent on a focus are a consequence of avoidance of stress-clash and the consequent deaccenting. In (18a), herself is a socalled intensifier which is claimed to be obligatorily accented in the literature. But in the presence of an adjacent narrow focus, accent on herself disappears. The same is true of the association with focus adjacent to a parallel focus in (18b), cf. Rooth (1992). In (18c), the answer to the question is completely deaccented. Instead the additive particle also carries the stress. (18d), from Reis \& Rosengren (1997), shows that a contrastive topic (Peter in Krifka's 1999 analysis) can also be realized without excursion if another, more prominent topic (Gauguin) is adjacent.

(22) a. Marie-Luise even grows RICE herself.

b. People who GROW rice only EAT rice. 
c. \{John said that Mark is coming, but what did Sue say?\}

She ALSO said that Mark is coming.

d. $\{$ Boy, Paul possesses a Gauguin. $\}$

Einen GAUGUIN besitzt Peter AUCH

'Peter also owns a Gauguin'

We see that there is no strict association between focus and accent or topic and accent. Accent is a preferred option but it is not obligatory. It is only present if the phonological structure of the sentence allows it. To sum up, the preference for associating some specific contours with IS roles, or just pitch accents can be explained by general properties of the language. ${ }^{2}$

\subsection{Morphological markers}

Morphological markers are compatible with the general claim of this section that the marking of focus and topic is always prosodically prominent if can be shown that the presence of a particle change the prosody of the sentence it appears in. Examples confirming this claim appeared in (11) for Japanese and in (15) for Cantonese topic markers. A number of tone languages have been studied as for their focus realizations which do not seem to have other correlates of IS than optional presence of morphological markers. Examples involving morphological markers for focus appear in the Gur languages Buli in (23) and Ditammari in (24), both from Fiedler et al. (to appear). In Buli, the focus marker kà precedes the focused constituent. But when the focused túe is sentence-initial, the marker kà is not obligatory. As for Ditammari, the focus marker nya follows the focused constituent.

(23) Q: What did the woman eat?

$$
\begin{aligned}
& \text { A: ò yòb kà túé. } \\
& \text { 3.SG eat FM beans } \\
& \text { 'She ate BEANS.' }
\end{aligned}
$$

(24) Q: What did the woman eat?

A: ò dī yātũrà nyā.

3.SG eat beans FM

'She ate BEANS.'

These markers have a delimiting function in creating a prosodic boundary. We thus propose that the prosodic connection of the focus and topic markers is to be found in the phrasing properties of a constituent delimited by such a marker. Even if not enough is known about the exact behavior of particles, it

2 Many languages do not use pitch accents to highlight a focused element, but rather raise the pitch register of a focused phrase as a whole. This happens for instance in Mandarin Chinese (Xu 1999), in Korean, in Georgian and in Hindi. 
seems to be a valid generalization that they always appear at the periphery of the constituent they mark.

In languages without special markers for IS, that is in languages which do not have pitch accent and which have only optional morphological markers, the answer to wh-question typically involves ellipsis of the given material. Only the constituent in focus is realized, a strategy which we propose to analyze in prosodic terms.

\section{To conclude}

This paper has proposed definitions of IS concepts in a model of information exchange that makes use of the notion of Common Ground. We also argued - in the limited place available - that there are universal principles in the way how IS roles are coded. One tendency, the tonal prominence of focused and the de-prominence of given expresseions, can be explained by the effort code (Gussenhoven 2004): Higher or lower expenditure in prosodic explicitness reflects the importance of subconstituents for communication. Others, like the tendency of topics to be prosodically separated from and to precede the rest, can be traced back to the optimal flow of information transmission. In spite of such commonalities, we have pointed out drastic differences in the ways how they are realized in the grammars of individual languages.

\section{References}

Beaver, David, Brady Zack Clark, Edward Flemming, T. Florian Jäger \& Maria Wolters. 2007. When semantics meets phonetics: Acoustical studies of second occurrence focus. Language 83. 245-276.

Bolinger, Dwight. 1958. A theory of pitch accent in English. Word 14. 109149.

Büring, Daniel. 2003. On D-trees, beans, and B-accents. Linguistics and Philosophy 26, 511-545.

Chafe, Wallace L. 1976. Givenness, contrastiveness, definiteness, subjects, topics and point of view. in Charles N. Li (ed.), Subject and Topic. 27-55. New York: Academic Press.

Cinque, Guglielmo. 1993. A null theory of phrase and compound stress. Linguistic Inquiery 24: 239-297.

Féry, Caroline, Gisbert Fanselow \& Manfred Krifka (eds.), The notions of Information Structure. Working Papers of the SFB632, Interdisciplinary Studies on Information Structure (ISIS) 6. Potsdam: 
Universitätsverlag Potsdam. http://www.sfb632.unipotsdam.de/isg.html.

Féry, Caroline \& Shinichiro Ishihara. 2005. Interpreting second occurrence focus. Ms. University of Potsdam.

Fiedler, Ines, Katharina Hartmann, Brigitte Reineke, Anne Schwarz \& Malte Zimmermann. To appear. Subject focus in West African languages. In Zimmermann, Malte \& Caroline Féry, Eds. Information Structure in Different Perspectives.

Frota, Sónia. 2000. Prosody and Focus in European Portuguese. New York: Garland Publishing.

Gussenhoven, Carlos. 2004. The phonology of tone and intonation, Cambridge University Press, Cambridge.

Halliday, M. A. K. 1967-68 Notes on transitivity and theme in English. Journal of Linguistics 3 \& 4.É. Kiss, Katalin (1998), "Identificational focus versus information focus", Language 74. 245-273.

Hartmann, Katharina \& Malte Zimmermann. 2007. In place -- out of place: Focus in Hausa.", in Kerstin Schwabe \& Susanne Winkler, On information structure, meaning and form, Amsterdam, John Benjamins, 365-403.

Horváth, Júlia. 1986. Focus in the Theory of Grammar and the Syntax of Hungarian. Dordrecht: Foris.

Hyman, Larry \& Maria Polinsky. To appear. Is there a focus position in Aghem? In: Zimmermann, Malte \& Caroline Féry, Eds. Information Structure in Different Perspectives.

Jackendoff, Ray. 1972. Semantic Interpretation in Generative Grammar. Cambridge, MA: MIT Press.

Jacobs, Joachim. 2001. The Dimensions of Topic-Comment. Linguistics 39: 641-681

Krifka, Manfred. 1999. Additive particles under stress. Proceedings of SALT 8. Cornell, CLC Publications. 111-128.

Liberman, Mark \& Janet Pierrehumbert. 1984. Intonational invariance under changes in pitch range and length. In Language Sound Structure, eds. Mark Aronoff \& Richard T. Oehrle. Cambridge, MA: MIT Press. 157-233.

Partee, Barbara H. 1999. Focus, quantification, and semantics-pragmatics issues. In Focus: Linguistic, Cognitive, and Computational Perspectives, eds. Peter Bosch \& Rob van der Sandt. Cambridge: Cambridge University Press. 213-231.

Reinhart, Tanya. 1982. Pragmatics and linguistics. An analysis of sentence topics. Philosophica 27. 53-94. 
Reis, Marga \& Inger Rosengren. 1997. A modular approach to the grammar of additive particles: The case of German auch. Journal of Semantics 14. 237-309.

Rizzi, Luigi. 1997. The fine structure of the left periphery. In Elements of Grammar: Handbook in Generative Syntax, ed. Liliane Haegeman, Dordrecht: Kluwer Academic Publishers. 281-337.

Rochemont, M. 1986. Focus in generative grammar. Amsterdam/ Philadelphia: John Benjamins Publishing Company.

Rooth, Mats. 1992. A theory of focus interpretation. Natural Language Semantics 1. 75-116.

Samek-Lodovici, Vieri. 2006. When right dislocation meets the leftperiphery: A unified analysis of Italian non-final focus. Lingua 116. 836-873.

Schwarzschild, Roger. 1999. GIVENness, AvoidF and other constraints on the placement of accent. Natural Language Semantics 7. 141-177.

Selkirk, Elisabeth O. 1995. Sentence prosody: Intonation, stress and phrasing. In Handbook of Phonological Theory, ed. John Goldsmith. Cambridge, MA: Blackwell. 550-569.

Stalnaker, Robert. 1974. Pragmatic presuppositions. in Milton K. Munitz \& Peter K. Unger (eds.), Semantics and Philosophy. 197-214. New York: New York University Press.

Steedman, Mark. 2000. Information Structure and the Syntax-Phonology Interface. Linguistic Inquiry 31. 649-689.

Szendröi, Kriszta. 2003. A stress-based approach to the syntax of Hungarian focus. The Linguistic Review 20 (1). 37-78.

$\mathrm{Xu}, \mathrm{Yi}$. 1999. Effects of tone and focus on the formation and alignment of F0 contours. Journal of Phonetics 27, 55-105.

Zerbian, Sabine. 2006. Expression of Information Structure in the Bantu Language Northern Sotho, Doctoral diss., Humboldt University, Berlin. 